\title{
Planning for Climate Change in Legacy Cities: The Case of Detroit, Michigan
}

NATALIE SAMPSON ${ }^{1}$, KIMBERLY HILL KNOTT ${ }^{2}$, DOMINIC SMITH ${ }^{3}$, LEILA MEKIAS ${ }^{2}$, JOEL HOWRANI HEERES ${ }^{4}$, SIMONE SAGOVAC 5 Volume 2, Fall 2014 http://dx.doi.org/10.3998/mjs.12333712.0002.004

${ }^{1}$ Department of Health and Human Services, University of Michigan-Dearborn, 19000 Hubbard Dr., Dearborn, Ml 48126

${ }^{2}$ Detroiters Working for Environmental Justice, 4750 Woodward Ave.,

Detroit, Michigan, 48201

${ }^{3}$ Michigan Department of Community Health, 201 Townsend Street, Lansing, Michigan, 48909

${ }^{4}$ EcoWorks, 4825 Michigan Avenue, Detroit, Michigan, 48210

${ }^{5}$ Southwest Detroit Community Benefits Coalition, Detroit, Michigan

Corresponding author: Natalie Sampson, nsampson@umich.edu

\section{ABSTRACT}

According to recent projections, by the end of the century, Detroit, Michigan's average summer temperature will rise by $7-13^{\circ} \mathrm{F}$. As a result, increased heat and heavy precipitation events will burden the city's infrastructure and population health, and likely lead to disproportionate distribution of related morbidity and mortality among the elderly, the chronically ill, and those who live in poverty-who comprise nearly $40 \%$ of the city's population. Meanwhile, over the last fifty years, Detroit has experienced perhaps the most severe economic downfall of all major U.S. cities, losing over half of its population and filing for bankruptcy in July 2013. As leaders struggle to rethink allocation of scarce municipal resources to meet residents' pressing basic needs, there has been effectively no capacity for climate change planning. Recognizing the compounding environmental and economic challenges residents face, Detroiters Working for Environmental Justice convened the Detroit Climate Action Collaborative (DCAC) in 2011. DCAC is an extensive planning effort involving diverse government, private, academic, and community partners. Its goal 
is to develop the city's first Climate Action Plan, which will document baseline greenhouse gas emissions, map vulnerabilities, engage leaders and residents, and translate this information into mitigation and adaptation strategies. In this paper, we introduce the barriers to and opportunities for climate planning in Detroit and other cities experiencing high levels of depopulation, vacant buildings and lots, and disinvestment. Specifically, we present the DCAC's planning process, accomplishments, and next steps as a unique case study of community-driven climate planning in a legacy city.

\section{Introduction}

According to the Intergovernmental Panel on Climate Change (2013), the frequency of heat waves and heavy precipitation is very likely to increase in most areas globally by the end of the twenty-first century. Recent trends call for concern. The United States (U.S.) broke more than 3,500 monthly weather records for heat, rain, and snow in 2012 (NOAA 2014). Ongoing climate change and an increase in the number of extreme weather events are likely to lead to higher incidences of morbidity, mortality, displacement, violence, and criminalization worldwide (IPCC 2013). These outcomes are projected to disproportionately affect the elderly, the very young, the poor, and those whose health is already compromised (Kovats and Hajat 2008). Further, the Stern Review estimates that the overall cost of inaction on climate change will reach the equivalent of 5-20\% of global gross domestic product (GDP) each year (Stern 2007). In an eight-country study that includes both developed and developing nations, the Economics of Climate Adaptation Work Group found that $40-68 \%$ of expected economic losses can be avoided through adaptation under a high-emissions scenario (UNEP, Oxfam, and World Resources Institute 2011). U.S. cities must prepare for climate change to prevent local health threats, economic decline, and related disparities.

In response, over 600 U.S. cities have developed climate action plans (CAPs) in the last few decades. These entail diverse mitigation and adaptation strategies that typically establish goals to reduce greenhouse gas emissions through land use, policy, or program interventions (Millard-Ball 2012). As cities have implemented these "first generation" climate plans, many scholars have started to evaluate them (Basset and Shandas 2010; Boswell, Greve, and Seale 2010; Millard-Ball 2012). They note that emission reduction goals vary extensively, many actions are voluntary, and insufficient resources limit implementation (Wheeler 2008). Even so, many scholars 
and municipal leaders generally agree that CAPs are useful and appropriate tools that cities can use to identify and address local risks of climate change, tailor adaptation and mitigation strategies to align with the institutions and legal and political tools of a particular region, and contribute to global reduction of greenhouse gas emissions (Snover et al. 2007).

\section{Climate Planning in Legacy Cities}

Legacy cities present a distinct context for climate planning. Legacy cities are those that have experienced a significant loss of industry and manufacturing employment since the mid-twentieth century, which contributed to depopulation through the mass suburbanization of residents (Mallach and Brachman 2013). The term 'legacy city' applies to places such as Buffalo, New York; Cleveland, Ohio; Detroit, Michigan; and Pittsburgh, Pennsylvania in the U.S. Scholars have also classified these places as 'shrinking' or 'post-industrial,' and no single term perfectly captures the dynamic changes happening across cities (Badger 2013). Discrimination by race and class underlie a host of complex social and economic processes that have accompanied depopulation in many of these cities. These processes have led to excessive vacant and abandoned houses and land, weak housing markets, unemployment, racial segregation, environmental contamination from past land uses, and concentrated poverty (Dewar and Thomas 2013; Massey and Denton 1993). Many of these cities have also engaged in contentious conversations regarding 'right-sizing' or 'strategic renewal' to better spatially match limited municipal services and resources to dispersed populations (Beauregard 2013; Metzger 2000).

Lack of available technology and decision support tools, institutional barriers, and limited information are challenges commonly faced by those working to implement climate adaptation strategies locally (Bierbaum and Stults 2013), and these challenges may be even greater in legacy cities that have relatively fewer economic or human resources. Schilling and Vasudevan (2013) studied how legacy cities in the U.S. engage in major sustainability initiatives. They reported that less than $5 \%$ of mayors who signed the U.S. Conference of Mayors Climate Protection Agreement were from cities with a population loss of $20 \%$ or greater between 1970 and 2010 . They also noted that only $2 \%$ of the 564 members of the International Council for Local Environmental Initiatives (ICLEI) Local Governments for Sustainability, as of August 2011, were from these depopulated cities. In 2013, the Rockefeller Foundation's 100 Resilient Cities Initiative selected no Midwest cities among the first 33 global grantees. In selected cities, the $\$ 100$ million program provides funding and 
technical support for creation and implementation of a resiliency plan and the hiring of a Chief Resiliency Officer to prepare for natural and manmade disasters. The North American grantees were largely coastal cities, including Berkeley, Boulder, El Paso, Jacksonville, Los Angeles, New York City, Oakland, and San Francisco; just one grantee-New Orleans-is often considered a legacy city.

In addition to lacking resources, legacy cities also face particular challenges regarding housing, neighborhood, and land use conditions, all of which are key factors in a community's vulnerability to climate change (Harlan et al. 2006; Rosenthal 2010). For instance, Rosenthal (2010) reported that housing code violations, the rate of dilapidated buildings, and property tax delinquencies were all predictors of heat-related mortality in New York City. These findings may translate to legacy cities such as Detroit, where tax foreclosures and blight are common occurrences (Dewar and Thomas 2013).

Despite these challenges, the picture is not entirely bleak for legacy cities that want to pursue climate change adaptation strategies. First, opportunities for climate planning have become increasingly widespread and accessible. For example, the U.S. Environmental Protection Agency (2013) recently released the open-access Local Greenhouse Gas Inventory Tool for Government Operations and piloted a Beta Module for community inventories. Second, legacy cities may actually be able to use their excess vacant land to advantage by pursuing innovative strategies to address extreme heat or precipitation events. For example, green infrastructure has been touted as a strategy to address urban heat islands, counter greenhouse gas emissions, and manage stormwater through redevelopment of vacant land using vegetation in diverse ways and scales in post-industrial cities (Schilling and Logan 2008).

While legacy cities lag behind other major U.S. cities in developing CAPs, many have recently begun to prepare plans that consider their legacy features. Table 1 lists several of these, as well as each city's level of depopulation and rate of housing vacancy. Cleveland, Ohio, which has lost nearly $56 \%$ of its population since 1950, lays out 33 action steps, including the following: "Become national leaders in reusing vacant land for renewable energy," "Develop a cost-effective approach to deconstructing and recycling demolished buildings," and "Prioritize sustainability and rightsizing in City infrastructure upgrades and improvements" (Sustainable Cleveland 2013). Baltimore, Maryland, which has lost nearly 35\% of its population since 1950, uses its CAP to emphasize the strategies of the Baltimore Office of Sustainability (2012) for caring for nearly 30,000 abandoned properties. Similarly, in Pittsburgh, which has experienced a nearly 55\% population loss since 1950, the 
CAP recommends policy incentives to support a vacant land management strategy following building demolition; it also discusses its Green Up program focused on converting city-owned vacant lots into community green spaces (Pittsburgh Climate Initiative 2008). Many cities must address population or economic growth in their CAPs (Adger, Arnell, and Tompkins 2005), but these examples illustrate how legacy cities must consider the opposite problems of depopulation, vacancy, and decline.

TABLE 1. Selected plans that address climate mitigation and adaptation in legacy cities experiencing major population loss.

\begin{tabular}{|c|c|c|c|}
\hline City & $\begin{array}{l}\text { Population Loss, } \\
\text { Peak Year-2010 } \\
\qquad(\%)^{1,2}\end{array}$ & $\begin{array}{l}\text { Housing } \\
\text { Vacancy Rate, } \\
2010(\%)^{3}\end{array}$ & Selected Plans \\
\hline $\begin{array}{l}\text { Baltimore, } \\
\text { MD }\end{array}$ & 34.6 & 15.8 & $\begin{array}{l}\text { Climate Action Plan, Baltimore Office of Sustainability (2012) } \\
\text { http://www.baltimoresustainability.org/climate-action-plan }\end{array}$ \\
\hline $\begin{array}{l}\text { Buffalo, } \\
\text { NY }\end{array}$ & 55.0 & 15.7 & $\begin{array}{l}\text { Comprehensive Plan, City of Buffalo (2004) } \\
\text { http://www.ci.buffalo.ny.us/files/1_2_1/mayor/cob_comprehensive_ } \\
\text { plan/section_245923343.html } \\
\text { Western New York Regional Sustainability Plan, Regional Planning } \\
\text { Consortium (2013) } \\
\text { http://uploads.oneregionforward.org/content/uploads/2013/06/ } \\
\text { Western-New-York-Regional-Sustainability-Plan.pdf }\end{array}$ \\
\hline $\begin{array}{l}\text { Cleveland, } \\
\mathrm{OH}\end{array}$ & 56.6 & 19.3 & $\begin{array}{l}\text { Cleveland Climate Action Plan: Building Thriving and Healthy } \\
\text { Neighborhoods, Mayor's Office of Sustainability (2013) } \\
\text { http://www.sustainablecleveland.org/about/climate-action-plan/ }\end{array}$ \\
\hline $\begin{array}{l}\text { Cincinnati, } \\
\mathrm{OH}\end{array}$ & 41.1 & 17.2 & $\begin{array}{l}\text { Green Cincinnati Plan, Office of Environment and Sustainability } \\
\text { (2013) } \\
\text { http://www.cincinnati-oh.gov/oeq/citywide-efforts/climate-protection- } \\
\text { green-cincinnati-plan/ }\end{array}$ \\
\hline $\begin{array}{l}\text { Detroit, } \\
\text { MI }\end{array}$ & 61.4 & 22.8 & $\begin{array}{l}\text { Detroit Climate Action Plan, Detroiters Working for Environmental } \\
\text { Justice (2015, expected) } \\
\text { http://www.dwej.org/do/dcac/ }\end{array}$ \\
\hline $\begin{array}{l}\text { New Orleans, } \\
\text { LA }\end{array}$ & 45.2 & 25.1 & $\begin{array}{l}\text { City of New Orleans Carbon Footprint Report, Office of Recovery } \\
\text { Management (2009) } \\
\text { http://www.nola.gov/getattachment/7aeaa7e4-7489-48f0-ac7b- } \\
\text { 4406c0926e79/Appendix-Ch-13-City-of-New-Orleans-Carbon- } \\
\text { Footprin/ }\end{array}$ \\
\hline $\begin{array}{l}\text { Pittsburgh, } \\
\text { PA }\end{array}$ & 54.8 & 12.8 & $\begin{array}{l}\text { Pittsburgh Climate Action Plan, Green Government Task Force of } \\
\text { Pittsburgh (2008) } \\
\text { http://www.city.pittsburgh.pa.us/district8/assets/08_pgh_climate_ } \\
\text { action_plan.pdf }\end{array}$ \\
\hline $\begin{array}{l}\text { Youngstown, } \\
\mathrm{OH}\end{array}$ & 60.6 & 19.0 & $\begin{array}{l}\text { Carbon Emissions Inventory, City of Youngstown (2011) } \\
\text { http://www.cityofyoungstownoh.org/Uploads/201151115744_- } \\
\text { Youngstown\%20GHG\%20Inventory\%20May\%202011.pdf }\end{array}$ \\
\hline
\end{tabular}

'Source: Dewar and Thomas (2013).

${ }^{2}$ Peak populations occurred in 1930 for Youngstown, 1960 for New Orleans, and 1950 for all other cities.

${ }^{3}$ Source: U.S. Census Bureau (2010). 


\section{The Case of Climate Planning in Detroit, Michigan}

The remainder of this article explores the barriers to and opportunities for climate planning in Detroit, Michigan, a legacy city that is currently developing a CAP. We present the planning process of the Detroit Climate Action Collaborative (DCAC) from 2011 to the present, describing its accomplishments and discussing its next steps. The DCAC narrative represents a unique case study of community-driven climate planning in the context of disinvestment.

\section{About Detroit, Michigan}

Between 2000 and 2010, Detroit's population declined from approximately 950,000 residents to 760,000 , and the number of vacant households rose from $10 \%$ to $30 \%$ between 2000 and 2010 (U.S. Census Bureau 2000, 2010). This is in stark contrast to the city's 1950 population of approximately 1.8 million residents (Dewar and Thomas 2013). Today, the remaining population is increasingly vulnerable. In 2000,14\% of residents were unemployed, and the mean household income was $\$ 29,500$; in 2010 , nearly $33 \%$ were unemployed, and the mean household income was $\$ 25,800$. The region's metropolitan planning organization projects that the population will continue to decline, to as few as 610,000 residents by 2030 (Grimes and Fulton 2012). Crude estimates suggest that $20 \%$ of the city is vacant, with nearly 150,000 vacant or abandoned parcels (DWP 2013). Meanwhile, according to a foundation-funded long-range planning initiative, Detroit Future Cities Strategic Framework, 88,000 residents remain in high-vacancy areas, and another 318,000 live in moderately vacant areas (DWP 2013) — more than half of the city's population in all. A local foundation has committed $\$ 150$ million to implement this framework, which includes strategies for redevelopment and economic revitalization.

Detroit has also experienced perhaps the most severe economic downfall of all major U.S. cities in the last fifty years, which has limited city-led environmental initiatives. When Ken Cockrel, Jr. became Interim Mayor upon removal of Kwame Kilpatrick in 2008, he instituted an Office of Sustainability. However, this office was removed due to financial concerns and downsizing at the beginning of Mayor Bing's administration in 2009. In March 2013, Michigan's governor authorized an Emergency Financial Manager to oversee Detroit's financial operations. In July 2013, the City filed for bankruptcy, leaving funding for employee pensions and 
health benefits in question. As the current city council struggles to rethink allocation of scarce municipal resources to meet residents' pressing basic needs, there has been effectively no capacity for climate change planning. Despite the lack of municipal resources, much environmental sustainability work has taken place under the leadership of community-based organizations. To integrate these efforts and call decision makers to action, in July 2013, a coalition of community-based organizations published the Detroit Environmental Agenda Report, which laid out the local policy context and made recommendations for addressing environmental issues related to air, water, energy, waste, housing, transportation, and neighborhoods in Detroit (DEA 2013).

\section{Climate Change and Health in Detroit}

Like most places around the world, Detroit is expected to experience the impacts of climate change over the next century. Climate change projections suggest several key concerns for Detroiters. In particular, the number of days per year with a high temperature above $90^{\circ} \mathrm{F}$ is projected to increase from 15 at present to between 36 and 72 by the end of the century (GLISA 2013). Experts estimate that if Detroit suffered the same extreme heat conditions that Europe did in the summer of 2003, it would experience over 450 excess deaths throughout the course of such a summer (Kalkstein et al. 2008). With warmer temperatures, there will be periods of drought interspersed with heavy storms, and more precipitation will fall in the form of rain rather than snow (GLISA 2013).

In combination, these changes may affect human health negatively in many ways. Principal concerns include injuries, violence, and fatalities related to severe weather events and heat waves; infectious diseases related to changes in vector biology and contamination of water and food; allergic symptoms related to increased allergen production; acute respiratory and cardiovascular events related to worsening air pollution and/or extreme temperatures; and nutritional shortages related to changes in food production (Frumkin et al. 2008). Globally, climate change impacts are expected to be worst for those with already compromised health, and a disproportionate number of Detroiters (as compared to residents of the entire state and country) experience compromised health (MDCH 2009). In 2010, the leading causes of death in Detroit were heart disease $(2,257)$, cancer $(1,583)$, cerebrovascular disease (371), accidents (318), and assault (270) (MDCH 2011) —most which are exacerbated by climate change. During the summer of 2013, there were 
859 reported heat-related emergency department visits between April 1 and August 31. This is likely an underestimate, since many Michigan hospitals do not participate in the Michigan Syndromic Surveillance System, and these occurrences are often misreported or unreported (MDCH 2013). In Detroit, the current prevalence of asthma among adults is $50 \%$ higher, and rates of asthma hospitalization are three times higher than those of Michigan as a whole (Wasilevich, Lyon-Callo, and Dombkowski 2008). Additionally, increased heat is likely to worsen respiratory illnesses globally, and local disparities may worsen.

\section{The Detroit Climate Action Collaborative (DCAC)}

In response to local climate projections and their implications for Detroit's most vulnerable populations, Detroiters Working for Environmental Justice (DWEJ) convened the DCAC in 2011. The DCAC's goals are twofold: 1) to develop the city's first CAP, documenting baseline greenhouse gas emissions from public and private sectors, mapping vulnerabilities, and projecting climate changes, and 2) to translate this information into actionable mitigation and adaptation strategies. The DCAC has had many accomplishments so far, made possible largely by funding from foundations, contributions of partner organizations, and community-academic partnerships. Table 2 describes five key elements of the CAP, each a major preliminary step necessary to shape the DCAC's strategies: 1) a climatology report, 2) a vulnerability assessment, 3) municipal and community greenhouse gas inventories, 4) a community engagement plan, and 5) workgroup recommendations.

The DCAC's structure includes a Steering Committee and topical area workgroups, which both guide the final content of the CAP. A DCAC Steering Committee comprised of community, government, and academic leaders makes overall decisions about processes and outcomes related to the CAP. Integral to the work of the DCAC are the topical area workgroups: 1) Businesses and Institutions, 2) Energy, 3) Homes and Neighborhoods, 4) Parks, Public Space, and Water Infrastructure, 5) Public Health, and 6) Solid Waste. Each workgroup is responsible for developing an action plan for its particular topic area that sets forth the local climate-related issues, goals, action steps, barriers, catalysts, key leaders, evaluation metrics, related job opportunities, and economic analyses. In November 2013 and June 2014, the workgroups came together for daylong events to review and discuss integration of their goals and actions. Final recommendations and corresponding action items are in progress, and many recognize Detroit's legacy features. For instance, the Homes 
and Neighborhoods workgroup considers Detroit's aging housing stock. Its members propose household weatherization strategies to mitigate related greenhouse gas emissions and to assist older homeowners in adapting to increased heat. In another instance, the Parks, Public Space, and Water Infrastructure workgroup recognizes Detroit's aging combined sewer water infrastructure. It proposes stormwater management strategies such as green infrastructure to prepare for increased heavy precipitation and flood events.

TABLE 2. Key components of the Detroit Climate Action Collaborative's climate action plan.

Climatology Report

Vulnerability Assessment

Greenhouse Gas Emissions Inventory

Community Engagement

Workgroup Recommendations
The DCAC partnered with the Great Lakes Integrated Sciences and Assessments Center (GLISA), a collaborative effort of Michigan State University and the University of Michigan, to conduct analyses and report on Detroit climatology. Analyses considered past and current trends in temperature, precipitation, air quality, water quality, and stormwater management. The analyses resulted in projections for heat-related mortality over the next century that the DCAC aims to prevent.

The DCAC partnered with the University of Michigan College of Architecture and Urban Planning to prepare vulnerability assessments for Detroit. A team of graduate students used spatial data to map various environmental factors including temperature, land cover type, soil type, slope, and amount/type of impervious surfaces; and risk factors including age, access to transportation, household income, and education level. Drawing on these data, they generated heat and flood vulnerability maps. Figure 1 provides a sample vulnerability map, which may help the DCAC to prioritize future CAP resources in evidence-based ways that consider spatial patterning of risk factors for heat-related morbidity and mortality.

The DCAC partnered with the University of Michigan Center for Sustainable Systems and the City of Detroit to develop the City's first comprehensive greenhouse gas inventory. A team of graduate students assessed municipal and city-wide sources of carbon dioxide, methane, and nitrous oxide for 2011 and 2012: buildings and facilities energy use; public transportation; municipal vehicle fleets; passenger car, truck, and on-road freight; industrial processes; solid waste landfill disposal and incineration; and wastewater treatment. This inventory will help to direct the DCAC's emissions-reduction goals, mitigation strategies, and creation of a baseline tracking system for regular emissions inventories.

The DCAC has developed an extensive community engagement plan, including focus groups with diverse stakeholders, a local climate summit, sector-specific meetings with business and faith communities, a public comment process on the CAP, a community survey, and documentary shorts in collaboration with local filmmakers. Public comments and key findings from the focus groups and surveys will inform and be reported in the CAP.

The DCAC convened the following 6 workgroups and charged them with developing mitigation and adaptation strategies for the DCAC Climate Action Plan: 1) Businesses and Institutions, 2) Energy, 3) Homes and Neighborhoods, 4) Parks, Public Space, and Water Infrastructure, 5) Public Health, and 6) Solid Waste. Workgroup members include community, government, academic, and business leaders with local and expert knowledge. Groups of 5-8 members have met regularly for over a year to assess related issues, goals, action steps, challenges, opportunities, leaders, and metrics related to their topic, culminating in a summary report that recommends strategies. 


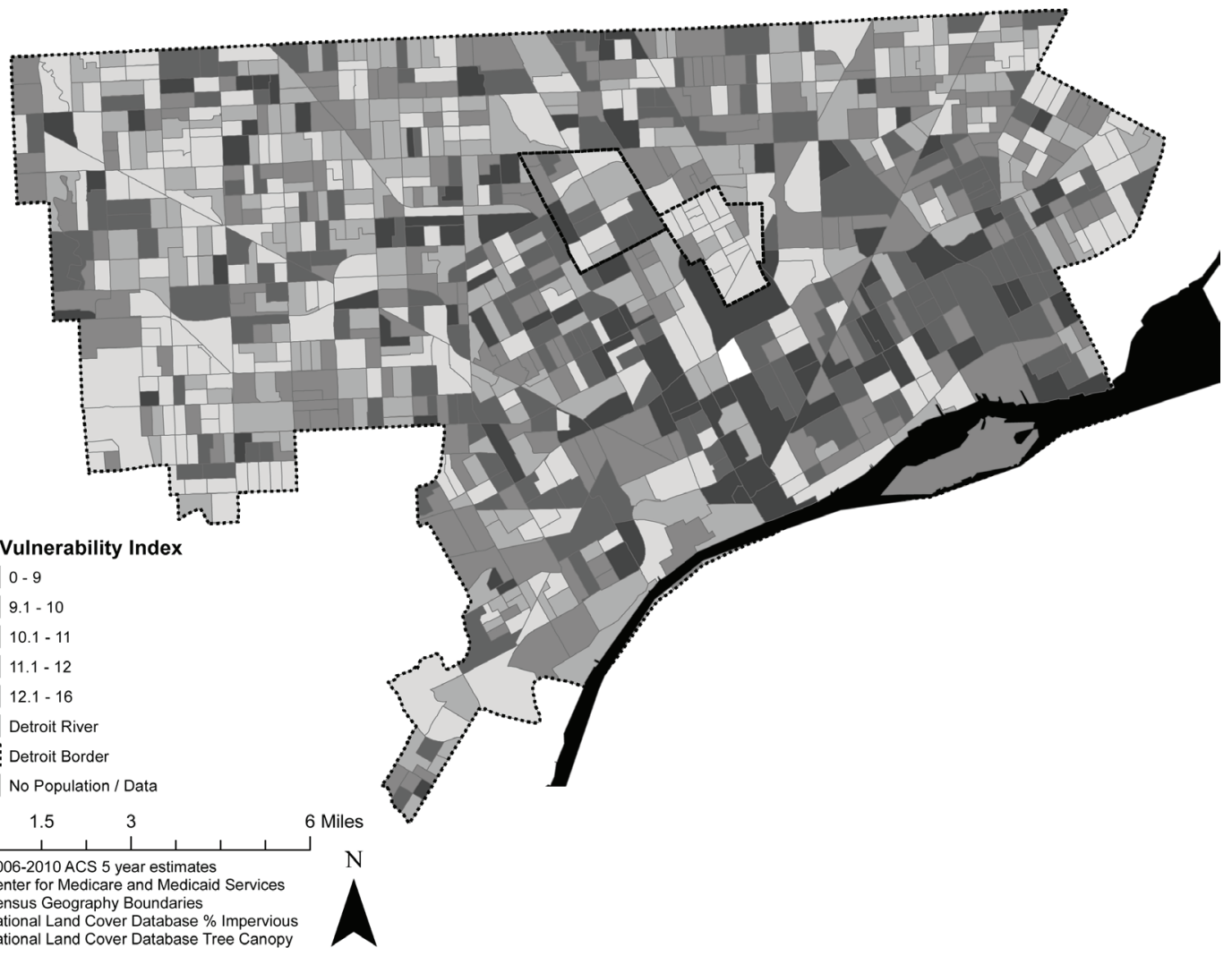

Figure 1. Heat vulnerability—Detroit, Michigan. ${ }^{*}$

${ }^{*}$ The Heat Vulnerability Index accounts for several variables, including \% of population over the age of $65, \%$ living alone, $\%$ persons of color, distance to water, prevalence of respiratory illness, $\%$ with less than a high school education, \% living below poverty, and \% impervious surface.

Map prepared by Evan Mallen, College of Architecture and Urban Planning, University of Michigan.

\section{Key Findings from DCAC Focus Groups}

As a first step in community engagement, between summer 2013 and winter 2014, the DCAC conducted a series of two-hour focus groups with different stakeholder groups, including environmental leaders $(n=8)$, city agency staff members $(n=6)$, and business leaders $(n=6)$, as well as two focus groups with residents $(n=6, n=12)$. Focus group participants were prompted to discuss the risks of climate change for Detroit, identify and prioritize preferred adaptation and mitigation strategies, inform community engagement approaches, and identify leaders already working on related initiatives. Approved by the University of Michigan Institutional Review 
Board, the focus groups were audiotaped, transcribed, de-identified, and analyzed for key themes.

Focus group participants offered the DCAC many early insights to consider before drafting and implementing the CAP, particularly in the context of Detroit's economic and environmental challenges. Environmental leaders spoke about the need for adequate mitigation goals and adaptation strategies that do not overburden already vulnerable or marginalized populations. Participants from government agencies noted how climate planning must be a cross-sector endeavor in local government and discussed the types of policies, funding, and metrics they would need to implement a CAP under current under-resourced conditions. Business leaders offered many innovative recommendations for outreach and education, including business sponsorship of vegetated 'green' roofs at industrial sites, rain gardens on vacant sites, and other demonstration projects or application software to communicate CAP-related resources and messages. Finally, residents described the ways that climate change relates to other issues in Detroit, such as air pollution, high asthma prevalence, blight, and violence, and they recommended integrated solutions that engage youth. They also called for the DCAC and other leaders to make the CAP and its outreach efforts relatable to Detroiters on multiple scales, with opportunities for districts, neighborhoods, and households to participate in implementing the CAP.

\section{Additional DCAC Activities}

In addition to preparing the CAP, the DCAC has engaged in a variety of other outreach and educational opportunities with local and federal partners. In early 2014, the DCAC collaborated with the Detroit Institute of Arts (DIA) and Wayne RESA, a regional educational service agency, to engage students at two Detroit schools in art projects related to climate change. Students toured the DIA to reflect on human interactions with the environment through art; they also created their own paintings, which were presented at a culminating exhibit at the DIA in May 2014. In June of 2016, the DCAC hosted leaders from the White House, Environmental Protection Agency, and Department of Energy for a "Climate Conversations" event to present the DCAC's work and discuss related federal climate change policies and programs. 


\section{The Detroit Climate Action Collaborative's Next Steps}

The DCAC's work is far from complete, and implementation of the CAP will require many additional steps. In spring 2015, the DCAC will release the CAP. Between 2014 and 2015, the DCAC will launch an aggressive community engagement program to raise awareness of climate change and its impact on Detroit, as well as introduce the DCAC and the CAP. The DCAC will develop strategies to assist residents in their own climate adaptation and mitigation efforts by creating a Detroit Climate Tool Kit in partnership with the Georgetown Climate Center. It will also facilitate a public comment process in which it solicits, addresses, and responds to the public's comments on the CAP at several small events and online forums. Additionally, the DCAC will continue to work with various partners to identify policy and economic opportunities related to the CAP that may spur job growth and training in Detroit. The group will also propose citywide and institutional policies to codify the CAP, working closely with local colleges and universities and government leaders to develop and promote policies that achieve mitigation and adaptation goals throughout Detroit. Finally, the DCAC is working to develop a clear CAP Implementation Plan to ensure that the goals developed through community engagement and by the six workgroups are fully enacted. This effort involves reaching out to government, foundation, and private entities to obtain resources and to determine the most appropriate leadership approach to long-term implementation.

The DCAC builds on major ongoing initiatives in Detroit, particularly the community-driven Detroit Environmental Agenda (DEA) and the foundationfunded Detroit Future Cities (DFC) Strategic Framework, which both recognize the legacy features of the city. Also convened by DWEJ in collaboration with several community partners, the DEA has issued a final report that provides government and community leaders with specific recommendations on how to achieve cleaner air, water, and energy; increased recycling; improved active transportation opportunities; and healthier land and housing. The DEA report draws attention to the city's current and legacy pollutants and calls for neighborhood care on vacant lots and properties. The DCAC's CAP may act as a companion piece to the DEA to inform community and city leaders of how the DEA's recommendations can be implemented in ways that also mitigate climate change or enable adaptation. The DFC Strategic Framework is a long-term vision that guides improvement of fiscal sustainability and quality of life in Detroit, focusing heavily on land use planning in a highly vacant context. The DCAC continues to work alongside the DFC, for instance, to understand how the green infrastructure and other land use interven- 
tions presented in the DFC framework might be designed to address vulnerability to heat and flood events as well.

\section{Discussion}

This paper has several limitations. In focusing on Detroit and its current climate planning efforts, it does not provide a comprehensive description of methods for developing, implementing, and evaluating a CAP that addresses vulnerabilities for all at-risk groups. Furthermore, our overview of other plans in legacy cities is necessarily brief and does not fully capture their diverse activities. Finally, it is too early to evaluate the implementation and implications of Detroit's CAP, and we do not offer the DCAC's approach as a prescription for all legacy cities. Despite these limitations, in sharing Detroit's experiences we provide a unique descriptive case study of community-driven climate planning led by an environmental justice organization in the context of severe disinvestment. This case study may give readers new perspectives on how legacy cities must approach climate planning differently from other U.S. cities.

As we have seen, legacy cities face added challenges when they embark on climate planning, such as blight; post-industrial pollution; and excess vacant land, commercial properties, and homes. CAPs from legacy cities also are fairly new, which suggests that legacy cities may benefit from ongoing dialogue among scholars and community and city leaders across the country about how to effectively leverage federal and foundation resources to address climate change impacts while limiting social, economic, and health disparities experienced by their residents.

Local leadership capacity and structure may affect climate planning and its subsequent outcomes. At its inception, the DCAC Steering Committee conducted an elaborate content analysis of existing CAPs and found few, if any, examples of community-led CAPs from which to garner lessons. Typically, municipal governments-not community organizations-convene stakeholders and lead the development of CAPs. However, Pittsburgh's plan, titled the Pittsburgh Climate Initiative, is led by a coalition of organizations in collaboration with city government (Sharrard and Jameson 2012). Over the last decade, Detroit's financial crisis prevented any major opportunities for municipally led climate planning, and DWEJ has followed a similar path of bringing in local organizations to lead this effort. The DCAC is still considering the most appropriate leadership approach to the CAP's long-term implementation. Pittsburgh and Detroit's community-led approaches 
could have applications in developing countries, as well as select U.S. cities, where non-profits take a substantial role in city governance (Berry et al. 2006).

Convened by DWEJ, the DCAC's climate planning process is also rooted in the principles of environmental justice (EJ) (Delegates to the First National People of Color Environmental Leadership Summit, 1991), which aims to engage marginalized populations and address the fundamental causes of vulnerability and the resulting disparities that are often overlooked by mainstream environmental efforts. In the U.S., President Obama announced a national CAP in June 2013, but the plan did not acknowledge the nation's EJ Executive Order 12898 signed by President Clinton in 1994 and it was drafted without input from historically engaged EJ leaders (EJ Leadership Forum 2013; Executive Office of the President 2013). While some CAPs include vulnerability mapping, many do not consider racial or economic inequities or explicitly address the well-being of populations who will be most vulnerable to climate change's health effects (Preston et al. 2011). By considering EJ concerns and priorities of community members early in the CAP planning process, cities may more successfully engage and protect vulnerable and marginalized populations.

\section{Conclusion}

Despite Detroit's many significant challenges and its uncertain future, the DCAC has experienced several early successes. The community-driven approach of the DCAC has engaged a robust network of community, academic, government, and private stakeholders. This has enabled DCAC to conduct a local climatology report, a greenhouse gas emission inventory, and vulnerability assessments; to work towards locally appropriate mitigation and adaptation strategies; and to begin an elaborate community engagement process. As recent CAPs from other legacy cities suggest, Detroit must identify strategies to protect vulnerable populations in preparation for climate change in concert with efforts to address current land use planning challenges. Without climate planning and supportive policies and resources, projected climate change is likely to exacerbate marginalization and the resulting health and economic disparities experienced by residents of legacy cities such as Detroit. 


\section{Acknowledgements}

The DCAC's accomplishments thus far were possible by the commitment of numerous community partners who comprise our steering committee and workgroups; while we cannot concisely name them all, we greatly appreciate their work. In particular, we would like to acknowledge the efforts of Daniel Brown and others at the Great Lakes Integrated Sciences and Assessment Center, who helped to develop the Detroit Climatology Report in collaboration with the DCAC. We also would like to express gratitude for the graduate students conducting our greenhouse gas inventory under the guidance of Drs. Rosina Beirbaum and Gregory Keoleian at the University of Michigan School of Natural Resources and the Environment, including Jill Carlson, Jenny Cooper, Marie Donahue, Max Neale, and Anis Ragland. We also appreciate the efforts of the graduate students who developed our first vulnerability assessments under the guidance of Drs. Larissa Larsen and Eric Dueweke at the University of Michigan College of Architecture and Urban Planning, including Kelly Gregg, Peter McGrath, Sarah Nowaczyk, Andrew Perry, Karen Spangler, Taylor Traub, and Ben VanGessel, as well as Evan Mallen, who prepared the sample heat vulnerability map in Figure 1. This work would not be possible without the generous contributions of the Fred A. and Barbara M. Erb Family Foundation, the DTE Energy Foundation, the University of Michigan School of Natural Resources and Environment Master's Project Funding, the University of Michigan Dow Interdisciplinary Award for Sustainability, and the Erb Institute for Global Sustainable Enterprise at the University of Michigan.

\section{References}

Adger, W. Neil, Nigel W. Arnell, and Emma L. Tompkins. 2005. "Successful Adaptation to Climate Change across Scales." Global Environmental Change 15 (2): 77-86.

Badger, Emily. 2013. "The Problem with Calling Cities 'Post-Industrial," CityLab, April 15. Accessed June 9, 2014. http://www.citylab.com/work/2013/04/problem-calling-cities-post-industrial $/ 5283 /$.

Baltimore Office of Sustainability. 2012. Climate Action Plan. Accessed June 9, 2014.

http://www.baltimoresustainability.org/climate-action-plan.

Bassett, Ellen, and Vivek Shandas. 2010. "Innovation and Climate Action Planning: Perspectives from Municipal Plans." Journal of the American Planning Association 76 (4): 435-450.

Beauregard, Robert A. 2013. "Strategic Thinking for Distressed Neighborhoods." In The City after Abandonment, edited by Margaret Dewar and June Manning Thomas, 268-288. Philadelphia: University of Pennsylvania Press. 
Berry, Jeffrey, Kent E. Portney, Robin Liss, Jessica Simoncelli, and Lisa Berger. 2006. Power and Interest Groups in City Politics. Cambridge, MA: Rappaport Institute for Greater Boston, Kennedy School of Government, Harvard University.

Bierbaum, Rosina, and Missy Stults. 2013. "Adaptation to Climate Change: Context Matters." Michigan Journal of Sustainability. Accessed June 9, 2014. http://dx.doi.org/10.3998/ mjs.12333712.0001.004.

Boswell, Michael, Adrienne Greve, and Tammy Seale. 2010. "An Assessment of the Link between Greenhouse Gas Emissions Inventories and Climate Action Plans." Journal of the American Planning Association 76:451-462.

Delegates to the First National People of Color Environmental Leadership Summit. 1991. Principles of Environmental Justice. Accessed June 9, 2014. http://www.ejnet.org/ej/principles.html.

Detroit Environmental Agenda. 2013. Detroit Environnemental Agenda Report. Accessed August 4, 2014. http://detroitenv.org/read-the-report/

Dewar, Margaret, and June Manning Thomas (eds.). 2013. The City after Abandonment. Philadelphia: University of Pennsylvania Press.

DWP (Detroit Works Project Long-Term Steering Committee). 2012. Detroit Future City: 2012 Detroit Strategic Framework Plan. Accessed August 4, 2014. http://detroitfuturecity.com/ framework/

Environmental Justice Leadership Forum. 2013. Close the EJ Gap. Accessed June 9, 2014. http:// www.ejleadershipforum.org/campaigns/.

Executive Office of the President. 2013. The President's Climate Action Plan. Washington, DC.

Frumkin, Howard, Jeremy Hess, George Luber, Josephine Malilay, and Michael McGeehin. 2008. "Climate Change: The Public Health Response." American Journal of Public Health 98 (3): 435-445.

Great Lakes Integrated Sciences Assessments (GLISA). 2013. The Potential Impacts of Climate Change on Detroit, Michigan. Accessed June 9, 2014. http://www.dwej.org/wp-content/uploads/2012/06/DCAC-Climate-Impacts-One-Pager.pdf.

Grimes, Donald, and George Fulton. 2012. Retrenchment and Renewal: The Economic and Demographic Outlook for Southeast Michigan through 2040. Accessed August 4, 2014. http://irlee. umich.edu/clmr/Docs/Outlook-SEMI-thru2040.pdf

Harlan, Sharon, Anthony J. Brazel, Lela Prashad, William Stefanov, and Larissa Larsen. 2006. "Neighborhood Microclimates and Vulnerability to Heat Stress." Social Sciences and Medicine 63 (11): 2847-2863.

IPCC (Intergovernmental Panel on Climate Change). 2013. "Summary for Policymakers." In Climate Change 2013: The Physical Science Basis. Contribution of Working Group I to the Fifth Assessment Report of the Intergovernmental Panel on Climate Change, edited by Thomas F. Stocker, Dahe Qin, Gian-Kasper Plattner, Melinda M. B. Tignor, Simon K. Allen, Judith Boschung, Alexander Nauels, Yu Xia, Vincent Bex, and Pauline M. Midgley. Cambridge, UK and New York: Cambridge University Press.

Kalkstein, Laurence S., J. Scott Green, David M. Mills, Alan D. Perrin, Jason P. Samenow, and Jean-Claude Cohen. 2008. "Analog European Heat Waves for U.S. Cities to Analyze Impacts on Heat-related Mortality." Bulletin of the American Meteorological Society 89 (1): 75-86.

Kovats, R. Sari, and Shakoor Hajat. 2008. "Heat Stress and Public Health: A Critical Review." Annual Review of Public Health 29 (9): 41-55. 
Mallach, Alan, and Lavea Brachman. 2013. Regenerating America's Legacy Cities. Cambridge, MA: Lincoln Land Institute.

Massey, Douglas, and Nancy Denton. 1993. American Apartheid: Segregation and the Making of the Underclass. Boston: Presidents and Fellows of Harvard College.

MDCH (Michigan Department of Community Health). 2009. 2009 Health Disparities Report.

- 2011. Geocoded Michigan Death Certificate Registry. Division for Vital Records and Health Statistics.

- 2013. Michigan Heat-Related Illness_Emergency Department Visits: 2013 Summary.

Metzger, John. 2000. "Planned Abandonment: The Neighborhood Life-Cycle Theory and National Urban Policy." Housing Policy Debate 11:7-40.

Millard-Ball, Adam. 2012. "Do City Climate Plans Reduce Emissions?” Journal of Urban Economics 71(3): 289-311.

NOAA (National Oceanic and Atmospheric Administration). 2014. Daily Weather Records, 2012. National Climatic Data Center. Accessed August 4, 2014. http://www.ncdc.noaa.gov/cdoweb/datatools/records

Pittsburgh Climate Initiative. 2008. Pittsburgh Climate Action Plan, Version 1.0.

http://www.city.pittsburgh.pa.us/district8/assets/08_pgh_climate_action_plan.pdf.

Preston, Benjamin, Richard Westaway, and Emma Yuen. 2011. "Climate Adaptation Planning in Practice: An Evaluation of Adaptation Plans from Three Developed Nations." Mitigation and Adaptation Strategies for Global Change 16 (4): 407-438.

Rockefeller Foundation. "100 Resilient Cities." Accessed June 9, 2014. http://100resilientcities. rockefellerfoundation.org.

Rosenthal, Joyce Klein. 2010. "Evaluating the Impact of the Urban Heat Island on Public Health: Spatial and Social Determinants of Heat-Related Mortality in New York City." PhD diss., Columbia University.

Schilling, Joseph, and Jonathan Logan. 2008. "Greening the Rust Belt: A Green Infrastructure Model for Right Sizing America’s Shrinking Cities." Journal of the American Planning Association 74 (4): 451-466.

Schilling, Joseph, and Raksha Vasudevan. 2013. "The Promise of Sustainability Planning for Regenerating Older Industrial Cities.” In The City after Abandonment, edited by Margaret Dewar and June Manning Thomas, 244-267. Philadelphia: University of Pennsylvania Press.

Sharrard, Aurora, and John Jameson. 2012. "Pittsburgh Climate Initiative: Advancing Sustainability through Organizational Collaboration." Global Business and Organizational Excellence 31 (4): 6-15.

Snover, Amy, Lara Whitely Binder, Jim Lopez, Elizabeth Willmott, Jennifer Kay, Doug Howell, and Jim Simmonds. 2007. Preparing for Climate Change: A Guidebook for Local, Regional, and State Governments. Oakland: ICLEI-Local Governments for Sustainability.

Stern, Nicholas. 2007. The Economics of Climate Change: The Stern Review. New York: Cambridge University Press.

Sustainable Cleveland. 2013. Cleveland Climate Action Plan. Accessed June 9, 2014. http://www. sustainablecleveland.org/about/climate-action-plan/.

United Nations Environment Programme (UNEP), Oxfam, and World Resources Institute. 2011. Adapting for a Green Economy: Companies, Communities and Climate Change.

U.S. Census Bureau. 2000. 2000: Decennial Survey. Accessed August 4, 2014. https://www.census. gov/mp/www/cat/decennial_census_2000/ 
2010. American Community Survey, 1-Year Estimates. Accessed August 4, 2014. http:// www.census.gov/acs/www/

U.S. Environmental Protection Agency. 2013. Local Greenhouse Gas Inventory Tool (LGGIT) for Government Operations User's Guide (Beta-version of Community Protocol and Software and Local Government Operations Protocol and Software). ICF International.

Wasilevich, Elizabeth A., Sarah Lyon-Callo, Ann Rafferty, and Kevin Dombkowski. 2008. Detroit-The Epicenter of Asthma Burden. Epidemiology of Asthma in Michigan. Michigan Department of Community Health, Bureau of Epidemiology.

Wheeler, Stephen. 2008. "State and Municipal Climate Change Plans: The First Generation." Journal of the American Planning Association 74 (4): 481-496. 